\title{
trans $-\left(\mathrm{P}(\mathrm{OPh})_{3}\right)_{2}(\mathrm{CO}) \operatorname{IrX}(\mathrm{X}=\mathrm{Cl}$ and $\mathrm{Br})$ : When
}

\section{changing chloro to bromo doesn't make much}

\section{difference}

\author{
Andreas Ross and Paul R. Sharp* \\ Department of Chemistry, University of Missouri-Columbia, 125 Chemistry Building, Columbia, \\ MO 65211-7600, USA \\ * Corresponding author at: E-mail address: sharpp@missouri.edu, Tel.: +1 5738827715
}

\begin{abstract}
Reinvestigation of trans- $\left(\mathrm{P}(\mathrm{OPh})_{3}\right)_{2}(\mathrm{CO}) \operatorname{IrCl} \mathbf{1}$ and trans- $\left(\mathrm{P}(\mathrm{OPh})_{3}\right)_{2}(\mathrm{CO}) \operatorname{IrBr} 2$ reveals unexpected coincidence in ${ }^{31} \mathrm{P}$ NMR, IR carbonyl stretch, and UV-visible absorption properties. XRD structure studies show the complexes are isostructural, although the crystals are not isomorphous. The complexes were investigated via DFT and TD-DFT modeling which shows that the spectroscopic similarity can be attributed to low-level halogen orbital participation in key molecular orbitals, a balance between the halogen atom $\sigma$ - and $\pi$-donation to the iridium center, and phenoxy group dominance of the phosphorus atom electronic structure.
\end{abstract}

Keywords: Iridium(I), phosphite, carbonyl, DFT, spectroscopy 


\section{Introduction}

Chemical compounds usually show distinct differences in their spectroscopic behavior (IR, NMR, UV-visible absorption, etc.) despite close analogy. For example, chloroform $\left(\mathrm{CHCl}_{3}\right)$ and bromoform $\left(\mathrm{CHBr}_{3}\right)$ are structurally and electronically analogous but have noticeably different ${ }^{1} \mathrm{H}$ and ${ }^{13} \mathrm{C}$ NMR chemical shifts, IR vibrational frequencies, and UV absorption band energies.[1-7] Such differences are also known for coordination complexes and changes in UVvisible absorption spectra are the basis for the spectrochemical series.[8]

The $\mathrm{d}^{8}$ square-planar platinum complexes trans- $\mathrm{Pt}\left(\mathrm{PEt}_{3}\right)_{2}(\mathrm{X})_{2}$ and trans- $\mathrm{Pt}\left(\mathrm{PEt}_{3}\right)_{2}(\mathrm{X})_{4}(\mathrm{X}=\mathrm{Cl}$, $\mathrm{Br}),[9-11]$ which we have been studying for halogen photoreductive elimination, show clear differences in ${ }^{31} \mathrm{P}$ NMR shifts, ${ }^{195} \mathrm{Pt}$ coupling constants, and UV absorption band energies and/or extinction coefficients on changing from $\mathrm{X}=\mathrm{Cl}$ to $\mathrm{X}=\mathrm{Br}$.[9-11] Data for the simplest members of this class, trans $-\mathrm{L}_{2} \mathrm{PtX}_{2}(\mathrm{X}=\mathrm{Cl}, \mathrm{Br})$, are shown in Table 1. Similarly, reported halo-carbonyl platinum complexes show distinct changes in IR carbonyl stretching energies upon halogen substitution $\left(\right.$ cis $-\mathrm{Pt}(\mathrm{CO})_{2} \mathrm{X}_{2}: v_{(\mathrm{CO})}=2187,2152 \mathrm{~cm}^{-1}$ for $\mathrm{X}=\mathrm{Cl}$ and $v_{(\mathrm{CO})}=2167,2122 \mathrm{~cm}^{-1}$ for $\mathrm{X}=\mathrm{Br}$ ).[12] We were therefore quite surprised when we prepared the known $\operatorname{Ir}(\mathrm{I})$ complexes trans $-\operatorname{Ir}\left(\mathrm{P}(\mathrm{OPh})_{3}\right)_{2}(\mathrm{CO}) \mathrm{Cl} 1$ and trans $-\mathrm{Ir}\left(\mathrm{P}(\mathrm{OPh})_{3}\right)_{2}(\mathrm{CO}) \mathrm{Br} 2$ and found nearly exact coincidence in their IR carbonyl stretching frequencies, their ${ }^{31} \mathrm{P}$ NMR shifts, and their UV-visible absorption spectra. Here, we report our efforts to understand why the change from bromo to chloro has so little effect on the spectroscopic properties of these Ir complexes. 
Table 1. Spectroscopic data ${ }^{\mathrm{a}}$ for trans $-\mathrm{L}_{2} \mathrm{PtCl}_{2}$ and trans $-\mathrm{L}_{2} \mathrm{PtBr}_{2}\left(\mathrm{~L}=\mathrm{PEt}_{3}\right)$

\begin{tabular}{|c|c|c|c|c|}
\hline Complex & $\lambda_{\max }(\mathrm{nm})$ & $\varepsilon\left(\mathbf{M}^{-1} \mathrm{~cm}^{-1}\right)$ & ${ }^{31} \mathbf{P} \mathbf{N M R}(\delta)$ & $J_{P t P}(\mathrm{~Hz})$ \\
\hline \multirow[t]{2}{*}{$\mathrm{L}_{2} \mathrm{PtCl}_{2}$} & 268 & 10258 & 12.9 & 2493 \\
\hline & 249 & 10386 & & \\
\hline \multirow[t]{2}{*}{$\mathrm{L}_{2} \mathrm{PtBr}_{2}$} & 285 & 6029 & 8.2 & 2333 \\
\hline & 253 & 5071 & & \\
\hline
\end{tabular}

\section{Results and Discussion}

Known complexes trans- $\left(\mathrm{P}(\mathrm{OPh})_{3}\right)_{2}(\mathrm{CO}) \operatorname{IrCl} 1[13]$ and trans $-\left(\mathrm{P}(\mathrm{OPh})_{3}\right)_{2}(\mathrm{CO}) \operatorname{IrBr} 2[14]$ are isoelectronic and are expected to be isostructural, belonging to the $\mathrm{d}^{8}$ square-planar family of complexes. Although obtained crystals of $\mathbf{1}$ and $\mathbf{2}$ are not isomorphous, single crystal XRD structure determinations confirm their isostructural nature and drawings of the two solid-state structures are shown in Figure 1. Mean metrical parameters for the two complexes are listed in Table 2 and show that Ir-P bond lengths are identical within 1 sigma, Ir-C bond lengths are identical within 2 sigma, and $\mathrm{C}-\mathrm{O}$ bond lengths are identical within 3 sigma. As expected, the iridium-halogen bond lengths are different and the $\mathrm{Ir}-\mathrm{Br}$ bond is $0.134 \AA$ longer than the $\mathrm{Ir}-\mathrm{Cl}$ bond, consistent with the $0.15 \AA$ greater covalent radius of Br.[15] The bond angles P1-Ir-P2 are similar, P-Ir-X are identical within 1 sigma, P-Ir-C are identical within 2 sigma and C-Ir-X are identical within 1 sigma. 


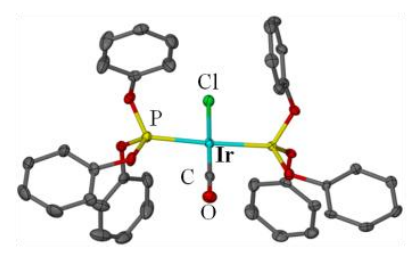

1

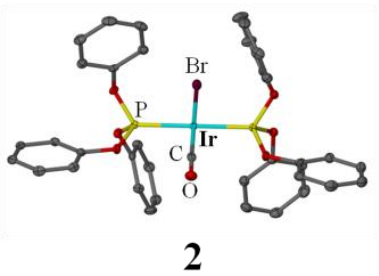

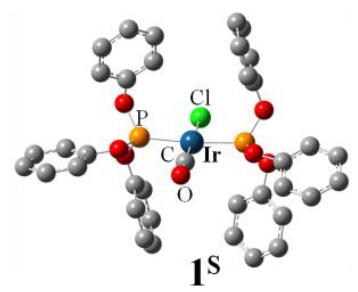

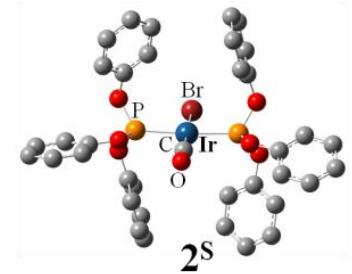

Figure 1. Solid-state structures of trans- $\left(\mathrm{P}(\mathrm{OPh})_{3}\right)_{2}(\mathrm{CO}) \operatorname{IrCl} 1$ and trans- $\left(\mathrm{P}(\mathrm{OPh})_{3}\right)_{2}(\mathrm{CO}) \operatorname{IrBr} 2$ (50\% thermal ellipsoids, hydrogen atoms omitted) and lowest-energy DFT model structures $\mathbf{1}^{\mathrm{S}}$ and $2^{\mathrm{S}}$ optimized in $\mathrm{CH}_{2} \mathrm{Cl}_{2}$.

Table 2. Selected metrical parameters ${ }^{a}\left(\AA\right.$ and degrees) for trans- $\left(\mathrm{P}(\mathrm{OPh})_{3}\right)_{2}(\mathrm{CO}) \operatorname{IrCl} 1$ and trans- $\left(\mathrm{P}(\mathrm{OPh})_{3}\right)_{2}(\mathrm{CO}) \operatorname{IrBr} \mathbf{2}$ and model complexes $\mathbf{1}^{\mathrm{S}}$ and $\mathbf{2}^{\mathrm{S}}$.

\begin{tabular}{|c|c|c|c|c|}
\hline Distance/ angle $^{\mathrm{a}}$ & 1 & 2 & $1^{S}$ & $2^{S}$ \\
\hline Ir-P & $2.2686(27)$ & $2.2660(1)$ & $2.3000(11)$ & $2.2956(4)$ \\
\hline $\mathrm{Ir}-\mathrm{X}^{\mathrm{c}}$ & $2.3530(12)$ & $2.4870(3)$ & 2.4236 & 2.5326 \\
\hline Ir-C & $1.830(5)$ & $1.853(3)$ & 1.822 & 1.830 \\
\hline $\mathrm{C}-\mathrm{O}$ & $1.143(6)$ & $1.125(4)$ & 1.160 & 1.159 \\
\hline P1-Ir-P2 & $176.73(4)$ & $177.04(3)$ & 177.40 & 174.22 \\
\hline C-Ir-P & $91.40(14)$ & $91.12(10)$ & $90.8(8)$ & $91.1(6)$ \\
\hline C-Ir-X $X^{c}$ & $179.47(15)$ & $179.43(10)$ & 177.97 & 177.73 \\
\hline P-Ir-X & $88.61(25)$ & $88.88(59)$ & $89.25(319)$ & $88.97(235)$ \\
\hline
\end{tabular}


${ }^{a}$ Mean values with standard deviations, where applicable. ${ }^{\mathrm{c}} \mathrm{X}=\mathrm{Cl}$ or $\mathrm{Br}$.

${ }^{31} \mathrm{P}$ NMR $\left(\mathrm{CDCl}_{3}\right)$ spectra for the complexes show a singlet at $\delta 104.9$ for both $\mathbf{1}$ and $\mathbf{2}$ with an external $\mathrm{H}_{3} \mathrm{PO}_{4}$ standard. Combining both complexes into a single NMR sample reveals two peaks with a small shift difference of $\delta 0.14$, with bromide 2 more downfield shifted. ${ }^{1} \mathrm{H}$ NMR spectra in $\mathrm{CDCl}_{3}$ are, expectedly, essentially identical and show a broad multiplet in the aromatic region for the phenyl protons of $\mathbf{1}$ and $\mathbf{2}$.

The infrared properties of $\mathbf{1}$ and $\mathbf{2}$ were studied elsewhere[13] and the carbonyl stretches are reported to be identical in chloroform and toluene solution. Our thin film FTIR investigation on $\mathrm{KBr}$ plates also shows identical IR carbonyl stretching energies with $v_{(\mathrm{CO})}=1999 \pm 4 \mathrm{~cm}^{-1}$ for $\mathbf{1}$ and $v_{(\mathrm{CO})}=1995 \pm 4 \mathrm{~cm}^{-1}$ for 2 . In contrast, the related platinum(II) complexes, cis-PtX $2(\mathrm{CO})_{2}$ and $\mathrm{Pt}_{2}(\mu-\mathrm{X})_{2} \mathrm{X}_{2}(\mathrm{CO})_{2}(\mathrm{X}=\mathrm{Cl}, \mathrm{Br}),[12]$ are reported to show different IR carbonyl stretching energies consequent to halogen substitution.

The UV-visible absorption spectra for $\mathbf{1}$ and $\mathbf{2}$ also appear identical (Figure 2).[16, 17] However, careful examination reveals minor differences in absorption maxima and extinction coefficients. The lowest energy absorption maximum for 1 appears at $436 \mathrm{~nm}\left(\square=582 \mathrm{M}^{-1} \mathrm{~cm}^{-1}\right)$ while that for 2 appears at $444 \mathrm{~nm}\left(\square=398 \mathrm{M}^{-1} \mathrm{~cm}^{-1}\right)$, and the second lowest energy absorption band for 1 is found at $382 \mathrm{~nm}\left(\square=5632 \mathrm{M}^{-1} \mathrm{~cm}^{-1}\right)$ while that for 2 is at $386 \mathrm{~nm}\left(\square=4602 \mathrm{M}^{-}\right.$ $\left.{ }^{1} \mathrm{~cm}^{-1}\right)$. A similar picture is observed for the higher energy absorption bands with the maxima and absorption coefficients shifted only slightly between the two complexes. The previously reported UV-visible absorption spectrum for $\mathbf{2}$ in toluene[16] (Table 2) is identical to that obtained here in dichloromethane, however the reported UV-visible absorption spectrum for $\mathbf{1}$ in toluene differs strongly in the second-lowest absorption band intensity (Table 3).[16] We therefore collected a 
Uv-vis absorption spectrum of a freshly prepared sample of $\mathbf{1}$ in toluene (Figure 2), which closely matches the spectrum in dichloromethane indicating little solvent polarity dependence. We are unable to reconstruct the difference in the second lowest energy band reported by Stohmeier.[16]

Table 3. UV-visible absorption data of $\mathbf{1}$ and $\mathbf{2}$

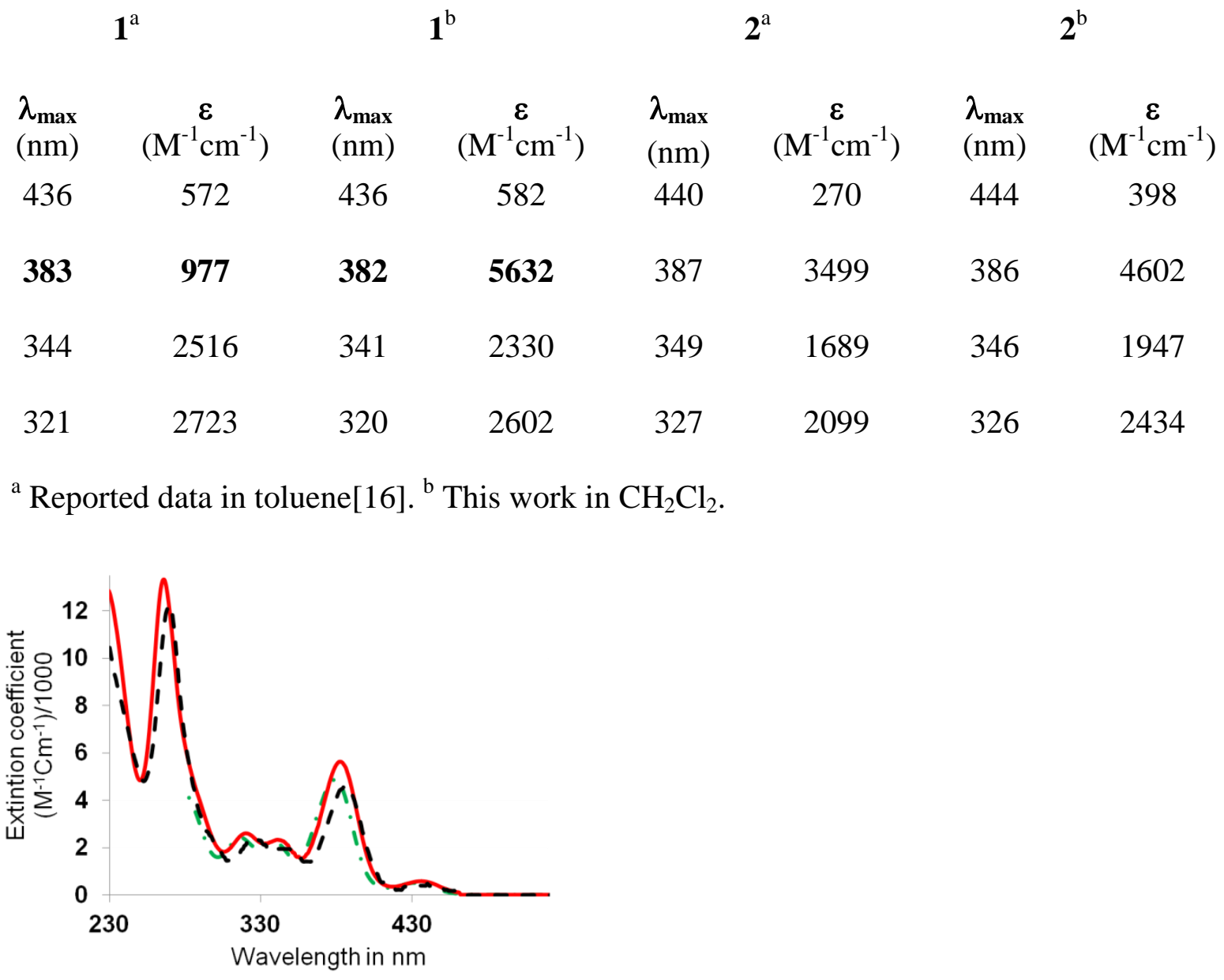

Figure 2. UV-vis absorption spectra for trans- $\left(\mathrm{P}(\mathrm{OPh})_{3}\right)_{2}(\mathrm{CO}) \mathrm{IrCl} \mathbf{1}$ in toluene (green dashdot), 1 in $\mathrm{CH}_{2} \mathrm{Cl}_{2}$ (red solid line) and trans- $\left(\mathrm{P}(\mathrm{OPh})_{3}\right)_{2}(\mathrm{CO}) \mathrm{IrBr} \mathbf{2}$ (black dashed line) in $\mathrm{CH}_{2} \mathrm{Cl}_{2}$.

DFT and TDDFT model calculations were completed to help understand the unexpected near identity of the above spectroscopic features of $\mathbf{1}$ and $\mathbf{2}$. Complete models (no group substitution) of $\mathbf{1}$ and $\mathbf{2}$ were constructed in GaussView and optimized in dichloromethane to give stationary 


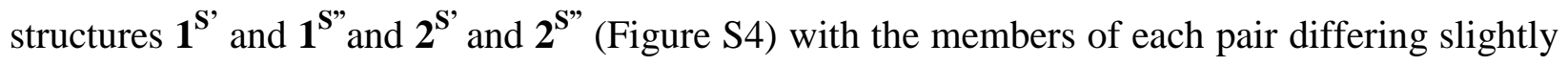
in the $\mathrm{P}(\mathrm{OPh})_{3}$ ligand orientation (no stationary point was found for $\mathbf{2}^{\mathrm{S}}$, see experimental). However, lower energy structures, $\mathbf{1}^{\mathrm{S}}$ and $\mathbf{2}^{\mathrm{S}}$ (Figure 1), with yet another $\mathrm{P}(\mathrm{OPh})_{3}$ ligand orientation, were obtained by importing the X-ray structures of $\mathbf{1}$ and $\mathbf{2}$ into GaussView and optimizing in dichloromethane. Structure $\mathbf{1}^{\mathbf{S}}$ ' and $\mathbf{1}^{\mathbf{S}}$ " are $2.6 \mathrm{kcal} / \mathrm{mol}$ and $5.4 \mathrm{kcal} / \mathrm{mol}$ less stable than $\mathbf{1}^{\mathbf{S}}$ and $\mathbf{2}^{\mathbf{S}}$ ' and $\mathbf{2}^{\mathrm{S} \text { "' }}$ are $0.6 \mathrm{kcal} / \mathrm{mol}$ and $6.1 \mathrm{kcal} / \mathrm{mol}$ less stable than $\mathbf{2}^{\mathrm{S}}$. Structures $\mathbf{1}^{\mathrm{S}}$ and $\mathbf{2}^{\mathbf{S}}$ are in good agreement with the crystal structures of $\mathbf{1}$ and $\mathbf{2}$ (Figure 1) with only slight changes from the optimization (Table 1).

With the optimized structures in hand the carbonyl vibrational modes were readily computed for isostructural $\mathbf{1}^{\mathrm{S}}$ and $\mathbf{2}^{\mathrm{S}}\left(v_{(\mathrm{CO})}=2064 \mathrm{~cm}^{-1}\right.$ and $\left.v_{(\mathrm{CO})}=2069 \mathrm{~cm}^{-1}\right)$ and differ by only $5 \mathrm{~cm}^{-1}$, identical within the experimental error of the measurements. Experimentally the carbonyl vibrational frequencies are reported to be essentially identical with $v_{(\mathrm{CO})}=2001-2003 \mathrm{~cm}^{-1}$ for trans $-\left(\mathrm{P}(\mathrm{OPh})_{3}\right)_{2}(\mathrm{CO}) \operatorname{IrX}(\mathrm{X}=\mathrm{Cl}, \mathrm{Br}, \mathrm{I}) \cdot[13]$ This identity was previously attributed to equivalent $\sigma$-bonds between the Ir center and the halogens and the absence of $\pi$-donation to the Ir center from the halogen lone pairs.[13] The HOMO-1 orbital (Figure 4) for model complexes $\mathbf{1}^{\mathrm{S}}$ (for $\mathbf{2}^{\mathrm{S}}$ see supplementary data) indicates that there is significant $\pi$-donation to the Ir center from the halogen atoms and it is intimately involved in back-donation to the CO ligand. A significant shift in the $\mathrm{CO}$ band would be expected from halogen substitution and, with $\mathrm{Cl}$ considered the stronger $\pi$-donor, $\mathbf{1}$ should display a lower CO stretching vibration than $\mathbf{2}$. However, the $\sigma$-interaction of the halogen atom with the metal center must also be considered and is expected to affect the $\mathrm{CO}$ stretching vibration in the opposite halogen order. That is, $\mathrm{Cl}$ is the weaker donor and in a $\sigma$-sense would give a higher $\mathrm{CO}$ stretching vibration for $\mathbf{1}$. The opposing $\pi$ - and $\sigma$-effects must be balanced for $\mathrm{Cl}, \mathrm{Br}$ and $\mathrm{I}$ in these $\mathrm{Ir}$ complexes such that the 
$\mathrm{CO}$ stretching vibration are essentially identical. For the $\mathrm{Pt}(\mathrm{II})$ complexes, cis- $\mathrm{Pt} \mathrm{X}_{2}(\mathrm{CO})_{2}$, the higher oxidation state and more contracted orbitals decrease the importance of $\pi$-bonding and the $\sigma$-effect dominates such that the $\mathrm{X}=\mathrm{Br}$ complex has the lower $\mathrm{CO}$ stretching vibrations $\left(v_{(\mathrm{CO})}=\right.$ 2187, $2152 \mathrm{~cm}^{-1}$ for $c i s-\mathrm{PtCl}_{2}(\mathrm{CO})_{2}$ and $v_{(\mathrm{CO})}=2167,2122 \mathrm{~cm}^{-1}$ for $\left.c i s-\mathrm{PtBr}_{2}(\mathrm{CO})_{2}\right)$.[12]

Calculated ${ }^{31} \mathrm{P}$ NMR $\left(\mathrm{CH}_{2} \mathrm{Cl}_{2}, \mathrm{PMe}_{3}\right.$ standard at $\delta$-62) shifts are also nearly the same for $\mathbf{1}^{\mathrm{S}}$ and $\mathbf{2}^{\mathrm{S}}$ with a shift difference of $\delta 0.56$. As experimentally observed for $\mathbf{1}$ and $\mathbf{2}$, the bromide $\mathbf{2}^{\mathrm{S}}$ is more downfield shifted. However, the absolute $\delta$ values are over estimated at $\delta 181.28$ for $\mathbf{1}^{\mathrm{S}}$ and $\delta 181.84$ for $\mathbf{2}^{\mathrm{S}}$ as compared to the experimental value of $\delta 104.9$ for $\mathbf{1}$ and $\mathbf{2}$. Nonetheless, the agreement is remarkable considering the difficulty caused by the presence of the Ir atom.[18, 19] Interestingly, ${ }^{31} \mathrm{P}$ NMR shifts of analogous complexes trans- $\mathrm{L}_{2}(\mathrm{CO}) \operatorname{IrX}\left(\mathrm{L}=\mathrm{PPh}_{3}, \mathrm{X}=\mathrm{Cl}\right.$, $\mathrm{Br})[20-22]$ are reported to be significantly different $(\sim \delta 2)$ for the bromo and chloro complexes despite similarity in CO stretching vibrational energy and UV-visible absorption properties. The difference in ${ }^{31} \mathrm{P}$ NMR shift sensitivity for the triphenylphosphine and triphenylphosphite complexes may be partly due to the difference in donor strength.[23] With a lower donor strength the phosphite ligand has a weaker interaction with the metal and so becomes less sensitive to electronic changes at the metal center. In addition, the $(\mathrm{PhO})_{3} \mathrm{P}$ unit appears to be less sensitive to electronic perturbation probably due to the strong interaction of the phenoxy group with the $\mathrm{P}$ center. For example, the $\delta$ shift difference for $\left[\mathrm{Ph}_{3} \mathrm{PCl}\right]^{+}$and $\left[\mathrm{Ph}_{3} \mathrm{PBr}\right]^{+}$is 15 units while that for $\left[(\mathrm{PhO})_{3} \mathrm{PCl}\right]^{+}$and $\left[(\mathrm{PhO})_{3} \mathrm{PBr}\right]^{+}$is only 2.7 units.[24] 

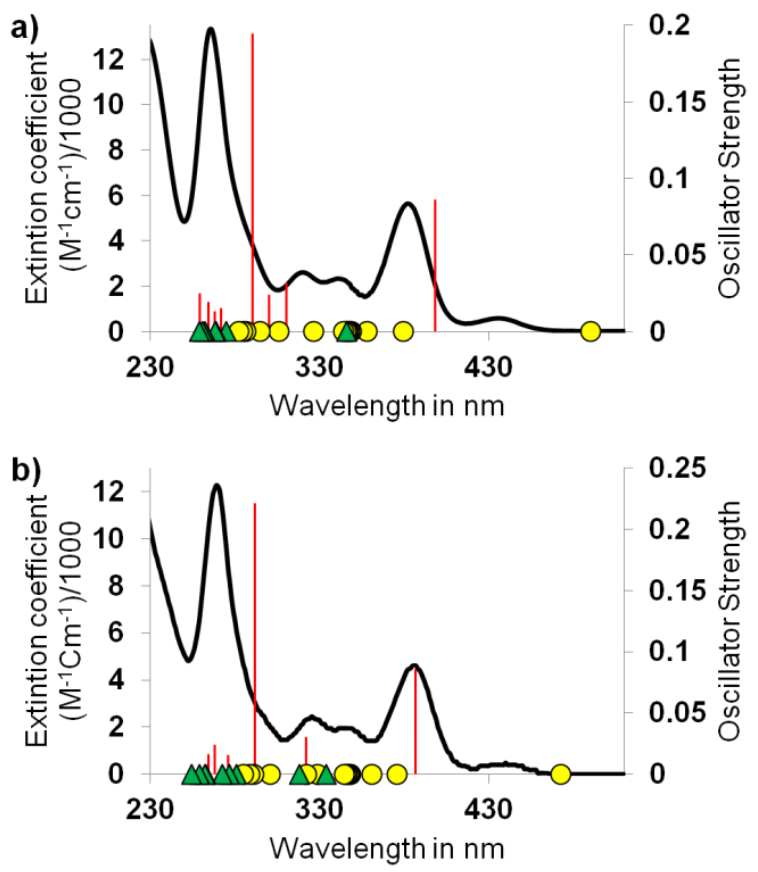

Figure 3. UV-vis absorption spectrum of a) $\mathbf{1}$ and b) $\mathbf{2}$ in dichloromethane (black line) and TDDFT (M06) vertical transitions (red vertical lines, height corresponds to the oscillator strength) for a) $\mathbf{1}^{\mathrm{S}}$ and b) $\mathbf{2}^{\mathrm{S}}$ in dichloromethane (smd). Yellow circles mark calculated triplet transitions and green triangles mark calculated dark (oscillator strength $<0.01$ ) singlet transitions.

Time-dependent DFT (TD DFT) calculations were performed to help analyze the UV-visible absorption spectra of $\mathbf{1}$ and 2. The calculated (M06) vertical transitions and their oscillator strengths (singlet-to-singlet) for $\mathbf{1}^{\mathrm{S}}$ and $\mathbf{2}^{\mathrm{S}}$ are compared with the experimental spectra in Figure

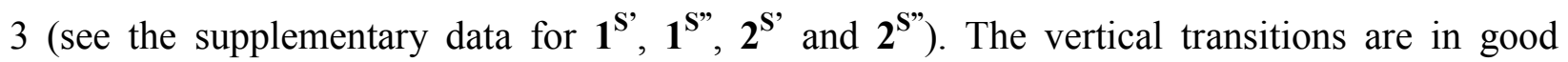
agreement with the experimental bands if the calculated transitions are scaled to higher energy. The weak, lowest-energy band in the experimental spectra of $\mathbf{1}$ and $\mathbf{2}$ match reasonably well with the M06 lowest-energy, formally spin forbidden, singlet-to-triplet vertical transitions (underestimated by $54 \mathrm{~nm}$ for $\mathbf{1}^{\mathrm{S}}$ and $29 \mathrm{~nm}$ for $\mathbf{2}^{\mathrm{S}}$ ). The second lowest absorption bands are more intense and match with the first spin allowed singlet-to-singlet vertical transitions being 
underestimated by $\sim 16 \mathrm{~nm}$ for $\mathbf{1}^{\mathrm{S}}$ and by $\sim 1 \mathrm{~nm}$ for $\mathbf{2}^{\mathrm{S}}$. The next higher energy bands, between $310 \mathrm{~nm}$ and $360 \mathrm{~nm}$, are weak and the calculations indicate a mixture of singlet-to-triplet vertical transitions and dark (oscillator strength $<0.01$ ) singlet vertical transitions in this area. The higher energy absorption bands $(<310 \mathrm{~nm})$ are matched by a series of singlet-to-singlet vertical transitions that are slightly underestimated. The calculations were repeated for $\mathbf{1}^{\mathrm{S}}$ and $\mathbf{2}^{\mathrm{S}}$ with the CAM-B3LYP functional. However, the CAM-B3LYP functional grossly underestimates the lowest-energy transition although it does match well with the higher-energy absorption bands (< $300 \mathrm{~nm}$ ) (see supplementary data).

Table 4. First two calculated lowest-energy vertical transition wavelengths (nm) for $\mathbf{1}^{\mathrm{s}}, \mathbf{1}^{\mathrm{s}}, \mathbf{1}^{\mathrm{s}}$, $\mathbf{2}^{\mathrm{S}}, \mathbf{2}^{\mathrm{S}}$, and $\mathbf{2}^{\mathrm{S} "}$.

$\begin{array}{lll}\begin{array}{l}\text { Complex } \\ \mathbf{1}^{\text {S }}\end{array} & \begin{array}{l}\text { Singlet-to-singlet } \\ \mathbf{1}^{\mathbf{S}^{\prime}}\end{array} & \begin{array}{l}\text { Singlet-to-triplet } \\ 498\end{array} \\ \mathbf{1}^{\mathrm{S}^{\prime}} & 388 & 468 \\ \mathbf{2}^{\mathrm{S}} & 388 & 463 \\ \mathbf{2}^{\mathbf{S}^{\prime}} & 376 & 473 \\ \mathbf{2}^{\mathrm{S}^{\prime}} & 380 & 453 \\ \end{array}$

Interestingly, the calculated absorption spectra are sensitive to the different $\mathrm{P}(\mathrm{OPh})_{3}$ ring orientations in $\mathbf{1}^{\mathrm{S}}, \mathbf{1}^{\mathrm{S}}, \mathbf{1}^{\mathrm{S} \prime} \mathbf{2}^{\mathrm{S}}, \mathbf{2}^{\mathrm{S}}$, and $\mathbf{2}^{\mathrm{S} "}$ (supplementary data and Table 4). However, the lowest-energy structures, $\mathbf{1}^{\mathrm{S}}$ and $\mathbf{2}^{\mathrm{S}}$, give the lowest-energy vertical transitions. The best fit for the experimental UV-vis absorption spectrum is obtained from the lowest-energy structure $\mathbf{2}^{\mathrm{S}}$ but the lowest-energy structure $\mathbf{1}^{\mathrm{S}}$ does not give the best fit to the UV-vis absorption spectrum of $\mathbf{1}$. 


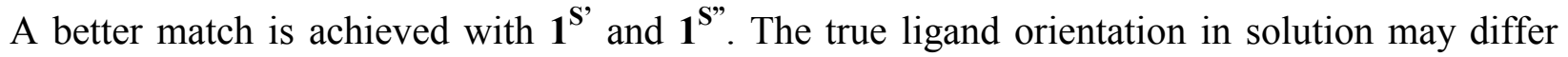
from the DFT predicted orientation and may be represented by a mix of the calculated structures.

To understand the sensitive to the ring orientations we examined the orbitals involved in the lowest-energy singlet-to-singlet and singlet-to-triplet vertical transitions. Both are predominantly HOMO-to-LUMO (see below) for all structures. The HOMOs are all essentially identical $\operatorname{Ir}_{z_{2}-}$ like orbitals. The LUMOs, which involve a $\pi$-type bonding interaction perpendicular to the square plane between the Ir center and the two $\mathrm{P}$ atoms and an antibonding interaction with orbitals on the phosphorus $\mathrm{O}$ atoms (Figure 4), show some differences due to rotation around one of the Ir-P bonds. In $\mathbf{1}^{\mathrm{S}}$ and $\mathbf{2}^{\mathrm{S}}$ the phosphite ligands are rotated so that the $\mathrm{O}$ atoms are staggered with respect to the Ir and P orbitals minimizing the antibonding interaction. In $\mathbf{1}^{\mathrm{S} \text { " }}$ and $\mathbf{2}^{\mathrm{S} \text { " }}$ one of the phosphite ligands is oriented such that one of the $\mathrm{O}$ atoms in eclipsed with the Ir-P $\pi$-type bond so that the antibonding interaction is increased. This increases the LUMO orbital energy, increasing the HOMO-LUMO gap and the LUMO<-HOMO transition energy.

The calculated vertical transitions for $\mathbf{1}^{\mathrm{S}}$ and $\mathbf{2}^{\mathrm{S}}$ were analyzed for the orbital composition of the departure and arrival orbitals in terms of percent contribution from iridium, carbonyl, phosphorous and halogen. GaussSum 3.0,[25] with its implemented partial density of states (PDOS) function was used to extract the orbital percent contributions.[26] The data are presented in Table 5 for the two lowest-energy singlet-to-triplet vertical transitions and the two lowest-energy singlet-to-singlet vertical transitions with significant $(>0.01)$ oscillator strength. Data for higher energy transitions are given in Table S29. As mentioned above, the lowestenergy transition for $\mathbf{1}$ and $\mathbf{2}$ is ascribed to a triplet excited state and is dominated (95\%) by a LUMO $\leftarrow$ HOMO component. The HOMO and LUMO orbitals are shown in Figure 4. The HOMO is mostly metal based $\mathrm{d}_{\mathrm{z2}}$-like, however the LUMO is highly mixed ( $\sim 40 \% \mathrm{Ir}, \sim 30 \% \mathrm{P}$ 
and $\sim 10 \% \mathrm{C}-\mathrm{O}$ orbital contribution) indicating that this transition consist of approximately $40 \%$ d-d (LF) character and $60 \%$ metal-to-ligand charge-transfer (MLCT) character making it a LF/MLCT. The second lowest energy transition for both complexes is ascribed to a singlet excited state with the same composition (LUMO $\leftarrow$ HOMO) as the lowest-energy triplet transition (96\% for $\mathbf{1}$ and $97 \%$ for $\mathbf{2}$ ). Thus, the first two lowest-energy transitions for $\mathbf{1}^{\mathrm{S}}$ and $\mathbf{2}^{\mathrm{S}}$ are LF/MLCT in character with a negligibly small halogen contribution, consistent with the small solvent polarity effect and the similarity of the UV-visible absorption spectra of $\mathbf{1}$ and $\mathbf{2}$.

The vertical transitions between $310 \mathrm{~nm}$ and $380 \mathrm{~nm}$ are more complex with less than $72 \%$ single orbital contributions for $\mathbf{1}^{\mathrm{S}}$ and $\mathbf{2}^{\mathrm{S}}$. The calculated singlet-to-singlet transitions in that region show significant halogen orbital involvement for $\mathbf{1}^{\mathrm{S}}(23 \%$ at $310 \mathrm{~nm})$ and for $\mathbf{2}^{\mathrm{S}}$ (36 \% at $322 \mathrm{~nm}$ and $318 \mathrm{~nm}$ ) but these transitions are dark (oscillator strength $<0.01$ ). The calculated singlet-to-triplet transitions in the same region show negligible and up to $29 \%$ halogen contribution for $\mathbf{1}^{\mathrm{S}}$ and $\mathbf{2}^{\mathrm{S}}$, but without knowledge of the oscillator strengths the contribution of these to the spectrum are not determined. 


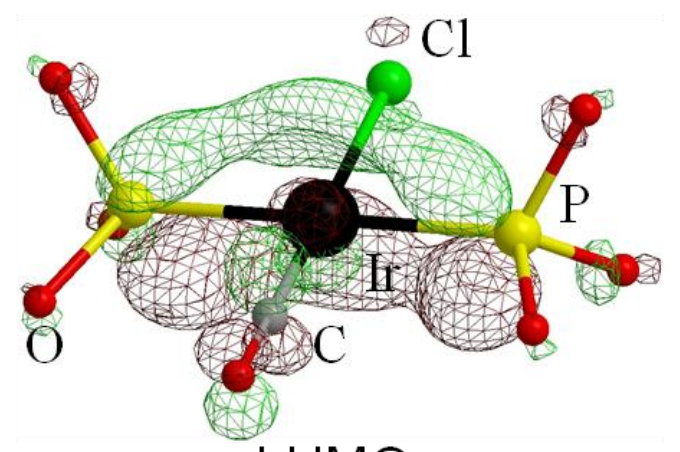

LUMO

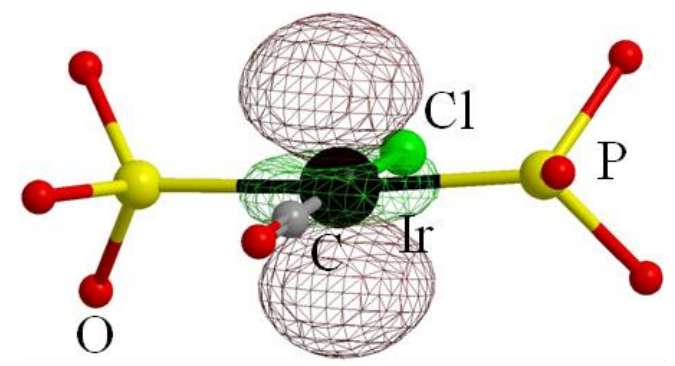

HOMO

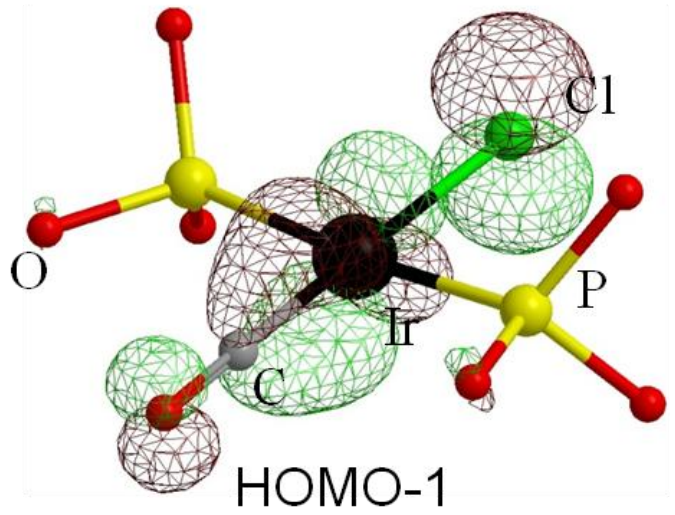

Figure 4. HOMO-1, HOMO and LUMO molecular orbital representations of $\mathbf{1}^{\mathrm{S}}$ with an isovalue of 0.052 (Phenyl rings omitted for clarity).

Electronic density difference maps (eddm) were used to visualize the change in electron density for the two lowest-energy singlet-to-singlet vertical transitions of $\mathbf{1}^{\mathrm{S}}$ (Figure 5). These also apply to the two lowest-energy singlet-to-triplet vertical transitions as they have essentially the same character. The first eddm is consistent with the LUMO $\leftarrow$ HOMO and LF/MLCT assignment involving electron transfer from metal to metal orbitals mixed with transfer from metal to ligand 
orbitals with negligible halogen contribution. The second eddm shows some halogen contribution but, again, this is a dark transition. The eddms for the other transitions are also consistent with the PDOS results (supplementary data) and both suggest that due to negligible halogen contribution to the absorption spectrum at lower energies $(>310 \mathrm{~nm})$ the absorption spectrum for $\mathbf{1}$ and $\mathbf{2}$ appear virtually identical.

Table 5. Selected calculated vertical transitions for $\mathbf{1}^{\mathrm{S}}$ and $\mathbf{2}^{\mathrm{S}}$ with departure and arrival orbital components (orbital contribution $>5 \%$ ) and the combined percent involvement of $\mathrm{Ir}, \mathrm{P}, \mathrm{Cl}$, and $\mathrm{CO}$ to the orbitals (M06 in dcm).

\begin{tabular}{|c|c|c|c|c|c|c|c|c|c|}
\hline \multicolumn{5}{|c|}{$1^{S}$ singlet-to-singlet } & \multicolumn{5}{|c|}{$2^{\mathrm{S}}$ singlet-to-singlet } \\
\hline \multirow{2}{*}{\multicolumn{5}{|c|}{$\begin{array}{l}\text { HOMO->LUMO }(96 \%) \\
398 \mathrm{~nm} \text {, oscillator strength }=0.0867\end{array}$}} & \multirow{2}{*}{\multicolumn{5}{|c|}{$\begin{array}{l}\text { HOMO->LUMO }(97 \%) \\
387 \mathrm{~nm} \text {, oscillator strength }=0.0862\end{array}$}} \\
\hline & & & & & & & & & \\
\hline & $\mathrm{Ir}$ & $\mathrm{P}$ & $\mathrm{Cl}$ & $\mathrm{CO}$ & & Ir & $\mathrm{P}$ & $\mathrm{Br}$ & $\mathrm{CO}$ \\
\hline departure (\%) & 92 & 0 & 0 & 1 & departure $(\%)$ & 87 & 0 & 0 & 2 \\
\hline arrival $(\%)$ & 39 & 30 & 2 & 11 & $\operatorname{arrival}(\%)$ & 38 & 27 & 3 & 12 \\
\hline \multirow{2}{*}{\multicolumn{5}{|c|}{$\begin{array}{l}\text { HOMO->L+1 }(83 \%), \mathrm{HOMO}->\mathrm{L}+10(6 \%) \\
346 \mathrm{~nm} \text {, oscillator strength }=0.0018\end{array}$}} & \multicolumn{5}{|c|}{ HOMO->L+1 (83\%), HOMO->L+10 (5\%) } \\
\hline & & & & & $334 \mathrm{~nm}$, oscilla & stre & $=0$. & & \\
\hline & $\mathrm{Ir}$ & $\mathrm{P}$ & $\mathrm{Cl}$ & $\mathrm{CO}$ & & Ir & $\mathrm{P}$ & $\mathrm{Br}$ & $\mathrm{CO}$ \\
\hline departure (\%) & 38 & 1 & 23 & 12 & departure $(\%)$ & 29 & 1 & 36 & 9 \\
\hline arrival (\%) & 36 & 28 & 2 & 10 & $\operatorname{arrival}(\%)$ & 34 & 24 & 3 & 10 \\
\hline \multicolumn{5}{|c|}{$1^{\mathrm{S}}$ singlet-to-triplet } & \multicolumn{5}{|c|}{$2^{\mathrm{S}}$ singlet-to-triplet } \\
\hline \multicolumn{5}{|c|}{$\begin{array}{l}\text { HOMO->LUMO (95\%) } \\
490 \mathrm{~nm}\end{array}$} & \multicolumn{5}{|c|}{$\begin{array}{l}\text { HOMO->LUMO }(95 \%) \\
473 \mathrm{~nm}\end{array}$} \\
\hline & $\mathrm{Ir}$ & $\mathrm{P}$ & $\mathrm{Cl}$ & $\mathrm{CO}$ & & Ir & $\mathrm{P}$ & $\mathrm{Br}$ & $\mathrm{CO}$ \\
\hline departure (\%) & 87 & 0 & 0 & 1 & departure (\%) & 86 & 0 & 0 & 2 \\
\hline arrival $(\%)$ & 37 & 29 & 2 & 10 & $\operatorname{arrival}(\%)$ & 38 & 27 & 3 & 11 \\
\hline \multicolumn{5}{|c|}{$\begin{array}{l}\text { HOMO->L+1 (72\%), H-1->LUMO (6\%), } \\
\text { HOMO->L+10 (6\%), } \\
380 \mathrm{~nm}\end{array}$} & \multicolumn{5}{|c|}{$\begin{array}{l}\mathrm{H}-1->\mathrm{LUMO}(70 \%), \mathrm{HOMO}->\mathrm{L}+1 \text { (12\%) } \\
376 \mathrm{~nm}\end{array}$} \\
\hline
\end{tabular}




\begin{tabular}{|lcccc|lllll|}
\hline & $\mathrm{Ir}$ & $\mathrm{P}$ & $\mathrm{Cl}$ & $\mathrm{CO}$ & & $\mathrm{Ir}$ & $\mathrm{P}$ & $\mathrm{Br}$ & $\mathrm{CO}$ \\
departure (\%) & 74 & 0 & 2 & 2 & departure (\%) & 35 & 1 & 29 & 8 \\
$\operatorname{arrival}(\%)$ & 27 & 18 & 4 & 5 & arrival (\%) & 32 & 22 & 3 & 9 \\
\hline
\end{tabular}

a)

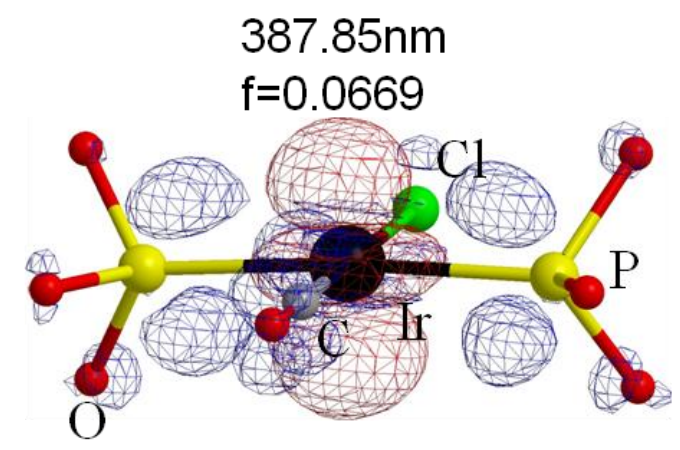

b)

$351.99 \mathrm{~nm}$

$\mathrm{f}=0.0042$

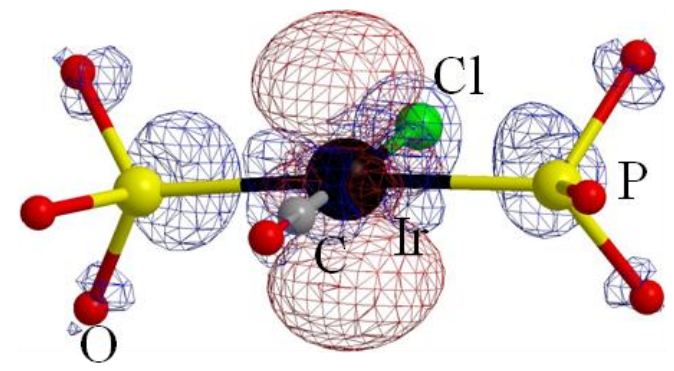

Figure 5. Electronic density difference map (eddm) of $\mathbf{1}^{\mathrm{S}}$ for the two lowest energy singlet-tosinglet vertical transitions (isovalue $=0.003$ ), a) first transition $\mathrm{b}$ ) second transition (dark). The red is where electron density is lost due to the transition and the blue is where it is gained (Phenyl rings omitted for clarity).

Like 1 and 2, trans- $\left(\mathrm{PPh}_{3}\right)_{2}(\mathrm{CO}) \operatorname{IrX}(\mathrm{X}=\mathrm{Cl}, \mathrm{Br}$ and $\mathrm{I})$ are reported to have nearly exact coincidence in their UV-visible absorption spectra.[16, 17] And, again like $\mathbf{1}$ and $\mathbf{2}$, the low energy absorption bands of $\mathrm{L}_{2}(\mathrm{CO}) \operatorname{IrX}(\mathrm{L}=$ phosphine; $\mathrm{X}=\mathrm{Cl}, \mathrm{Br})$ were assigned as metal-to- 
ligand charge transfer (MLCT), with the lowest having triplet character.[17] This assignment is closely matched with our TD-DFT results, where the first two lowest energy absorption bands are predicted to be $\mathrm{a}^{3} \mathrm{LF} / \mathrm{MLCT}$ and LF/MLCT.

\section{Conclusions}

Identical IR carbonyl stretching energies for $\mathrm{L}_{2}(\mathrm{CO}) \operatorname{IrX}(\mathrm{X}=\mathrm{Cl}, \mathrm{Br}$ and $\mathrm{I})$ appear to be due to a balanced $\sigma$ - and $\pi$-interaction of the halogen atom with Ir center resulting in an insignificant change of electron density on the Ir center on changing halide ligands. Virtually identical UVvisible absorption spectra for $\mathbf{1}$ and $\mathbf{2}$ are attributed to the negligible halogen atom contribution to the low-energy electronic transitions $(>310 \mathrm{~nm})$. The near coincidence in the ${ }^{31} \mathrm{P}$ NMR shifts is unique to the triphenylphosphite complexes $\mathbf{1}$ and $\mathbf{2}$ and is probably due dominance of the phenoxide groups on the electronic structure around the $\mathrm{P}$ atom.

\section{Experimental}

General. trans- $\left(\mathrm{P}(\mathrm{OPh})_{3}\right)_{2}(\mathrm{CO}) \operatorname{IrCl} 1[13]$ and trans- $\left(\mathrm{P}(\mathrm{OPh})_{3}\right)_{2}(\mathrm{CO}) \operatorname{IrBr} 2[14]$ were prepared according to literature procedures. Reagents were purchased from commercial sources (Aldrich or Acros) and used as received. Experiments were performed under a dinitrogen or argon atmosphere in a Vacuum Atmospheres Corporation drybox or on a Schlenk line unless otherwise indicated. Solvents were dried, degassed (freeze-pump-thaw) and stored under dinitrogen over 4 $\AA$ molecular sieves or sodium metal unless otherwise noted. Solution NMR spectra were recorded on Bruker AMX-250 or -300 spectrometer at ambient probe temperatures. NMR shifts are given in $\delta$ with positive values downfield of TMS $\left({ }^{1} \mathrm{H}\right)$ and external $\mathrm{H}_{3} \mathrm{PO}_{4}\left({ }^{31} \mathrm{P}\right) .{ }^{31} \mathrm{P}$ NMR spectra were recorded in proton-decoupled mode. Uv-vis spectra were recorded on a Cary 50 or 
Hewlett-Packard 8452 diode array spectrophotometer in $1 \mathrm{~cm}$ quartz cells. IR spectra were recorded on a Thermo Nicolet 670 spectrophotometer on $\mathrm{KBr}$ plates thin films by evaporation of $\mathrm{CH}_{2} \mathrm{Cl}_{2}$ solutions. Once the solvent evaporated the IR spectra were obtained. The crystals were grown from a saturated toluene solution at $-20^{\circ} \mathrm{C}$ in a Vacuum Atmospheres Corporation drybox.

DFT details. Gaussian 09[27] with the M06[28] or CAM-B3LYP[29] (TD DFT) functional were used for all calculations The TDDFT calculations for $\mathbf{1}$ and $\mathbf{2}$ included solvent effects (smd model[30]). The LANL2TZ[31] basis set was employed for iridium and cc-pVdZ[32] for all other atoms. Initial structures were imported from CIF files or generated in GaussView[33] without simplification. All geometries were optimized without symmetry constraints. For $\mathbf{2}^{\mathbf{S}}$, a stationary point was found probably due to a shallow potential energy surface (during the final stages of the optimization the energy change was negligibly small). The lowest energy structure of $\mathbf{2}^{\mathbf{S}}$ ' was used for the energy calculations. Analytical frequency calculations gave no imaginary frequencies for the complexes except for $\mathbf{2}^{\mathbf{S}}$, which had a small imaginary frequency of -8.9 $\mathrm{cm}^{-1}$ associated with motion of the phenyl rings of $\mathrm{P}(\mathrm{OPh})_{3}$. Free energies, enthalpies, and entropies were calculated at $298.15 \mathrm{~K}$ and $1 \mathrm{~atm}$. Optimized structures $\mathbf{1}^{\mathrm{S}}, \mathbf{2}^{\mathrm{S}}$ and with the M06[28] functional were used for the ${ }^{31}$ P NMR calculations (NMR=CSGT IOp(10/93=1, solvent $=\mathrm{CH}_{2} \mathrm{Cl}_{2}$ ). Due to the absence of symmetry in the structures, the NMR calculations predict two $\mathrm{P}$ atom shifts for $\mathbf{1}^{\mathrm{S}}$ and $\mathbf{2}^{\mathrm{S}}$. The two shifts were averaged to give the calculate ${ }^{31} \mathrm{P}$ NMR shifts. Shifts are relative to a $\mathrm{PMe}_{3}$ standard $(\delta-62)$. Coordinates, energies and ${ }^{31} \mathrm{P} N \mathrm{NR}$ data are given in the supplementary data. 
Supplementary Data. CIF files and DFT data (coordinates, energies, eddm figures, PDOS table, MO figures, TD DFT results and simulated ${ }^{31}$ P NMR). CCDC 1025312 (1), 1025313 (2) contains the supplementary crystallographic data for this paper. These data can be obtained free of charge from The Cambridge Crystallographic Data Centre via www.ccdc.cam.ac.uk/data_request/cif.

\section{Corresponding Author}

* Correspondence to Paul R. Sharp (sharpp@missouri.edu).

\section{Author Contributions}

The manuscript was written through contributions of all authors. All authors have given approval to the final version of the manuscript.

Acknowledgements. Support was provided by the U. S. Department of Energy, Office of Basic Energy Sciences (DE-FG02-88ER13880). We thank Dr. Charles Barns for X-ray data collection and processing and Dr. Wei Wycoff for assistance with the NMR measurements. The computations were performed on the HPC resources at the University of Missouri Bioinformatics Consortium (UMBC).

\section{References}

[1] W.M. Litchman, D.M. Grant, J. Am. Chem. Soc. 90 (1968) 1400-1407.

[2] G.R. Fulmer, A.J.M. Miller, N.H. Sherden, H.E. Gottlieb, A. Nudelman, B.M. Stoltz, J.E. Bercaw, K.I. Goldberg, Organometallics 29 (2010) 2176-2179.

[3] J. Nishida, S. Shigeto, S. Yabumoto, H.-O. Hamaguchi, J. Chem. Phys. 137 (2012) 234501234510 . 
[4] C. Hubrich, F. Stuhl, J. Photochem. 12 (1980) 93-107.

[5] G.C. Causley, B.R. Russell, J. Chem Phys. 62 (1975) 848-857.

[6] Coblentz Society, Inc, Evaluated Infrared Reference Spectra, NIST Standard Reference Database Number 69. Eds. P.J. Linstrom and W.G. Mallard, National Institute of Standards and Technology, Gaithersburg MD, 20899, 2014, http://webbook.nist.gov, September 5, 2014.

[7] V. Talrose, E.B. Stern, A.A. Goncharova, N.A. Messineva, N.V. Trusova, M.V. Efimkina, A.N. Yermakov, A.A. Usov, A.A. Goncharova, A.N. Leskin, N.A. Messineva, M.V. Efimkina, UV/Visible Spectra, in NIST Chemistry WebBook, NIST Standard Reference Database Number 69. Eds. P.J. Linstrom and W.G. Mallard, National Institute of Standards and Technology, Gaithersburg MD, 20899, 2014, http://webbook.nist.gov, September 5, 2014.

[8] D.F. Shriver, P.W. Atkins, T.L. Overton, J.P. Rourke, M.T. Weller, F.A. Armstrong, Inorganic Chemistry, 4th ed., Oxford University Press, Great Britain, 2006, Page 461.

[9] A.R. Karikachery, H.B. Lee, M. Masjedi, A. Ross, M.A. Moody, X. Cai, M. Chui, C.D. Hoff, P.R. Sharp, Inorg. Chem. 52 (2013) 4113-4119.

[10] A.R. Karikachery, P.R. Sharp, Bromine Photoelimination from Organoplatinum(IV)

Complexes, Dissertation, University of Missouri-Columbia, 2014.

[11] T.A. Perera, M. Masjedi, P.R. Sharp, Inorg. Chem. 53 (2014) 7608-7621.

[12] F. Bagnoli, D.B. Dell'Amico, F. Calderazzo, U. Englert, F. Marchetti, A. Merigo, S. Ramello, J. Organomet. Chem. 622 (2001) 180-189.

[13] W. Strohmeier, T. Onoda, Z. Naturforsch. Teil b 23 (1968) 1377-1379.

[14] B.J. Fisher, R. Eisenberg, Inorg. Chem. 23 (1984) 3216-3222.

[15] W.W. Porterfield, Inorganic chemistry, a unified approach, Addison Wesley Publishing Co., Reading Massachusetts, USA, 1983.

[16] W. Strohmeier, F.J. Muller, Z. Naturforsch. Teil b 24 (1969) 770-773. 
[17] R. Brady, B.R. Flynn, G.L. Geoffroy, H.B. Gray, J.J. Peone, L. Vaska, Inorg. Chem. 15 (1976) 1485-1488.

[18] M. Bühl, M. Kaupp, O.L. Malkina, V.G. Malkin, J. Comput. Chem. 20 (1999) 91-105.

[19] C.J. Cramer, Essentials of Computational Chemistry: Theories and Models 2nd ed., John Wiley \& Sons, Chichester, 2004, Pages 344-345.

[20] P.E. Garrou, G.E. Hartwell, Inorg. Chem. 15 (1976) 646-650.

[21] K.D. Schramm, T.H. Tulip, J.A. Ibers, Inorg. Chem. 19 (1980) 3183-3185.

[22] R.A. Vanderpool, H.B. Abrahamson, Inorg. Chem. 24 (1985) 2985-2989.

[23] C.A. Tolman, Chem. Rev. 77 (1977) 313-348.

[24] E. Krawczyk, A. Skowronska, J. Michalski, J. Chem. Soc., Dalton Trans. (2002) 4471-4478.

[25] N.M. O'Boyle, A.L. Tenderholt, K.M. Langner, J. Comp. Chem. 29 (2008) 839-845.

[26] N.M. O'Boyle, A.L. Tenderholt, K.M. Langner, GaussSum, version 3.0

http://gausssum.sourceforge.net/DocBook/, June 1, 2014.

[27] M.J. Frisch, G.W. Trucks, H.B. Schlegel, G.E. Scuseria, M.A. Robb, J.R. Cheeseman, G. Scalmani, V. Barone, B. Mennucci, G.A. Petersson, H. Nakatsuji, M. Caricato, X. Li, H.P. Hratchian, A.F. Izmaylov, J. Bloino, G. Zheng, J.L. Sonnenberg, M. Hada, M. Ehara, K. Toyota, R. Fukuda, J. Hasegawa, M. Ishida, T. Nakajima, Y. Honda, O. Kitao, H. Nakai, T. Vreven, J.A. Montgomery, J.E.P. Jr., F. Ogliaro, M. Bearpark, J.J. Heyd, E. Brothers, K.N. Kudin, V.N. Staroverov, R. Kobayashi, J. Normand, K. Raghavachari, A. Rendell, J.C. Burant, S.S. Iyengar, J. Tomasi, M. Cossi, N. Rega, J.M. Millam, M. Klene, J.E. Knox, J.B. Cross, V. Bakken, C. Adamo, J. Jaramillo, R. Gomperts, R.E. Stratmann, O. Yazyev, A.J. Austin, R. Cammi, C. Pomelli, J.W. Ochterski, R.L. Martin, K. Morokuma, V.G. Zakrzewski, G.A. Voth, P. Salvador, J.J. Dannenberg, S. Dapprich, A.D. Daniels, Ö. Farkas, J.B. Foresman, J.V. Ortiz, J. Cioslowski, D.J. Fox, Gaussian 09 Revision C.01; Gaussian, Inc., Wallingford CT, 2010 (2009).

[28] Y. Zhao, D.G. Truhlar, Acc. Chem. Res. 41 (2008) 157. 
[29] T. Yanai, D.P. Tew, N.C. Handy, Chem. Phys. Lett. 393 (2004) 51-57.

[30] A.V. Marenich;, C.J. Cramer;, D.G. Truhlar, J. Phys. Chem. B 113 (2009) 6378-6396.

[31] L.E. Roy, J.P. Hay, R.L. Martin, J. Chem. Theory and Comput. 4 (2008) 1029-1031.

[32] D. Feller, J. Comput. Chem. 17 (1996) 1571-1586.

[33] R. Dennington, T. Keith, J. Millam, GaussView, version 5, Semichem Inc., Shawnee Mission KS 2009. 